\title{
O homem na publicidade da última década. Uma cultura em mutação?
}

\section{Men in advertisement in the last decade. A changing culture?}

\author{
Flailda Brito Garboggini*
}

\begin{abstract}
RESUMO
Procuramos focalizar estereótipos masculinos, examinando alguns modelos da publicidade dos últimos dez anos. Discutimos algumas mudanças na sociedade, enfrentadas pelo homem atualmente. Retomamos uma tipologia de gênero baseada na semiótica. Apontamos algumas transformações e diferenças atuais de apresentação dos homens na publicidade. Palavras-chave: comunicação, representação masculina, publicidade.
\end{abstract}

\begin{abstract}
The phocus of this work lies on masculine stereotypes, examining advertisement models, in the last 10 years. We discuss some changes that man is dealing, nowadays in society. We returned to a gender typology based on semiotics. We point out some current changes and differences in the way men are presented in ads.

Key-words: communication, masculine representation, advertisement.
\end{abstract}

Nas três últimas décadas, temos acompanhado as transformações dos papéis femininos e masculinos na sociedade, estudando a representação de gênero no discurso publicitário. À luz da semiótica, analisamos diversos co-

* Doutora em Ciências da Comunicação (ECA-USP). Pós-doutora em Semiótica - Université Lumière-Lyon 2. Professora da Pontifícia Universidade Católica de Campinas (Pucamp) 
merciais de televisão, formulando uma tipologia dos estereótipos de gênero que retomamos, em parte, neste trabalho (GARBoGginI, 1999). Concentramonos, prioritariamente, em anúncios de revistas brasileiras, francesas e italianas, tendo como escopo observar o prosseguimento, exclusivamente, das mudanças nas representações do masculino na publicidade, comparando as tendências do Brasil com as da França e da Itália.

Fundamentando-nos em Octávio Ianni (2000, p.132), consideramos a intensa abrangência e influência da mídia globalizada nos dias de hoje. Efetivamente, os meios de comunicação colocam-se no âmago do mundo da cultura, das condições e possibilidades de representação e imaginação.

"Aquele que trabalha com os meios de representação, principalmente quando pode manipular as mais diversas linguagens e as mais diferentes técnicas, pode levar as representações a extremos de paroxismos". Contudo, acreditamos que a publicidade costuma acompanhar com cuidado as tendências na direção mais aceitável de uma sociedade em um determinado período. $\mathrm{Na}$ verdade, para cada tipo de produto é adotado um posicionamento e, conseqüentemente, uma personalidade representada por algum estereótipo. Assim, espelha-se na própria cultura, mas considera o consumidor alvo, com suas particularidades, para atingi-lo melhor. Sem dúvida, reforça padrões de conduta pré-estabelecidos pelos referenciais dominantes de uma época e, isso, ao longo do tempo, pode interferir na formação das atitudes da sociedade, mudando lentamente a cultura.

No caso das características de gênero, muitas razões nos levam a supor que as novas formas de representação do homem no final do século XX e no início deste estão sendo decorrentes de variáveis importantes na sociedade, não apenas devidas às lutas femininas pela igualdade de direitos, mas também por movimentos em prol dos direitos das minorias excluídas por questões de raça, credo ou preferência sexual ao longo das últimas décadas. A conscientização foi aumentando e, hoje, a sociedade ocidental começa a ser mais acessível a novas propostas em relação às apresentações de pessoas nas mais diversas formas de comportamento. A publicidade veiculada em alguns países da Europa, em comparação com a do Brasil, parece mais arrojada nesse sentido, considerando as proporções dos avanços culturais das sociedades.

Contudo, apesar das mudanças no comportamento e desempenho das mulheres e as reivindicações de maior aceitação dos homossexuais nas últimas décadas, na maioria dos países ocidentais a posição do homem permaneceu quase sem alterações. Por muito tempo, ele colocou-se, apenas, como observador das transformações pelas quais o desempenho feminino veio passando, sem a preocupação com o que e em que isso interferiria em seu próprio papel. 
Historicamente, o homem se sente muito mais cobrado em sua masculinidade do que as mulheres em sua feminilidade. Ele precisa provar freqüentemente sua virilidade. Desde criança, é desafiado a demonstrar ser um homem.

O Brasil é um país machista? Talvez, mas não tanto quando comparado aos outros latino-americanos. Conforme Lima, em pesquisa publicada na revista Época (30/05/2005, p. 86), “as premissas 'homem não chora' e 'lugar de mulher é em casa' são rejeitadas pela maioria dos brasileiros do sexo masculino. Os mexicanos são os que mais concordam com essas afirmações. Os brasileiros são também os que mais aceitam realizar trabalhos domésticos, enquanto os argentinos são os que menos encaram esse tipo de tarefa. Aqui, $76 \%$ acreditam que a mulher deve trabalhar fora".

Ainda nos parece cedo dizer que o brasileiro não é machista, mas alguns sinais estão aparecendo para mostrar que algumas coisas estão mudando.

\section{Pressupostos e tendências}

Partimos do pressuposto de que a publicidade, enquanto linguagem plurissígnica, reforça os padrões de comportamento estabelecidos pela sociedade dominante ou idealizada, refletindo a realidade e a refratando de forma idealizada para ser atraente e fixar uma imagem positiva de marca. Somente com uma ótima estratégia de marketing, composta por propaganda, preço, produto e distribuição, cada empresa poderá alcançar, realmente, seu público alvo, convencendo-o a adotar seus produtos.

Por muito tempo, as imagens do homem dominador e conquistador foram estabelecidas como padrões ideais. A publicidade refletiu isso por muito tempo, até quando essas referências começaram a ser postas em questão por parte da sociedade, que tomou consciência de suas desvantagens. Nesse contexto, em que o modelo masculino tradicional detinha o poder, a parcela feminina encontrou meios para combater e conseguiu realizar transformações. Protestaram, inclusive, contra a propaganda que a desvalorizava, principalmente em países como França e Inglaterra, centros de movimentos feministas.

Segundo Randazzo (1997, p.185), durante a década de 1980, a figura do homem guerreiro, ou o machão, nos EUA, "passou a ser alvo de ataques e 
houve uma mudança para uma imagem masculina mais suave, mais sensível e paternal. Os homens dos anos noventa, entretanto, começaram a queixar-se e a dizer que estavam perdendo contato com a sua masculinidade".

Essa tendência transpareceu mais na mídia brasileira no final dos anos 90, notadamente, nas classes mais altas e no meio acadêmico. Outros tipos de comportamento masculino começaram a ser destacados e aceitos como, por exemplo, o homem que assume sua sensibilidade. Cresceu, nos últimos cinco anos, o número de reportagens, tratando de forma positiva o "homem sentimental", recentemente, chamado como "metrossexual"1 - definido como "hetero, mas com vaidade quase feminina". ${ }^{2}$

Nesse contexto, parece que a publicidade, entre outros produtos da mídia, interfere sugerindo a adoção de novos produtos e serviços de um modo moderno, associado à aquisição de novos hábitos. Assim, os homens sentem-se incentivados a expressar melhor sua sensibilidade, deixando os medos, a vaidade e outros sentimentos apresentarem-se sem receio de serem discriminados como menos masculinos.

\section{O homem da última década - convivência entre o tradicional e o novo}

O sexo masculino veio perdendo posições com o incremento da população feminina no mercado de trabalho. Hoje, cerca de $24 \%$ das mulheres brasileiras são chefes de família, ou seu trabalho sustenta o lar. Dados do IBGE mostram que a participação das mulheres no mercado de trabalho subiu para $48 \%$. Elas continuam de forma madura a luta pelos seus direitos, estão mais conscientes e unidas nesta conquista, pois já há muitas décadas começaram esta busca.

Assim, começa a ser comum a permanência do homem em trabalhos domésticos. Porém, para grande parte dos brasileiros parece existir, ainda,

1 Metrossexual é um termo adotado pela mídia internacional, por volta de 2003, pela junção das palavras metropolitano e heterossexual, sendo uma gíria para um homem urbano excessivamente preocupado com a aparência; gastando muito com cosméticos, acessórios e roupas de marca.

2 “Nem gay nem machão" (FALK, J. L'Espresso, Roma, 29/01/04, p. 130). 
grande dificuldade na aceitação dessa imagem. O homem lavando pratos ou lavando roupas ainda é algo raramente visto na publicidade brasileira. A idéia do homem cozinheiro não é mais tão estranha, porém vem de longa data com os chefes de cozinha, os mais famosos e melhores na preparação de pratos sofisticados. Tornou-se até mesmo algo "glamouroso", desde que executado e valorizado por homens.

Até os anos 1980, a publicidade apresentava o homem sendo servido pela mulher e, na imagem de pai, apenas, em situações de lazer com os filhos, dando-lhes conselhos ou comprando-lhes presentes.

De acordo com algumas pesquisas e em reportagens publicadas nos últimos tempos, o homem brasileiro começou a enfrentar uma fase de crise. Cushnir (1994, p. 35) discute sobre o masculinismo, alertando para os problemas dessas mudanças de hábitos, decorrentes de mudanças dos papéis masculinos. Para ele, o homem não estava preparado para lidar com as mulheres profissionalmente superiores, independentes e que tomam iniciativas.

Com efeito, no final da década de 1990, muitos artigos e reportagens mostravam a incerteza dos homens diante das mudanças. O psicólogo Sócrates Nolasco trata apropriadamente da "crise masculina" e do "homem de verdade" (2001, p. 73-105). Para ele, o homem não sabia o que fazer diante de uma nova cultura que se estabelece, onde a presença feminina se alterou intensamente.

Efetivamente, é normal que os homens sintam a necessidade de uma nova preparação para si e para criar seus filhos, principalmente, os meninos. Precisam correr para recuperar o tempo perdido. Não tendo acreditado no estabelecimento dessas mudanças, foram pegos de surpresa. Ainda hoje, poucos estão conseguindo tratar de assuntos com os filhos sobre a nova masculinidade e sobre a possível perda da exclusiva liderança e autoridade.

Efetivamente, todos os membros da família têm o acesso à informação. Hoje, até mesmo as crianças pequenas recebem um fluxo intenso de comunicação pela televisão, Internet e telefonia celular, mídias cada vez mais avançadas e acessíveis.

A antiga imagem masculina adulta acabou dando lugar a uma massa disforme em busca de uma identidade. Os produtos da mídia, em geral, dão a medida de como esse descontrole da situação atingiu o homem hoje.

Nesse contexto, qual é o papel do homem? Que espaço ocupa a figura do pai na mente dos filhos? Qual é a importância de seus conselhos e de suas opiniões?

No início da década de 1990, eram poucos os pais que davam aos filhos a imagem deste homem novo. Já existia uma barreira tripla a ser enfrentada: 
o questionamento da virilidade ancestral, a aceitação de uma temida feminilidade e a invenção de uma nova masculinidade. As mudanças não ocorrem facilmente, apesar das contestações.

Atualmente, é comum aos homens não apenas a demanda pela mudança de papéis mas, também, o fato de terem que lidar com forças mundiais tais como ênfase cada vez maior na educação formal e maior instabilidade dos mercados de trabalho.

\section{Retomando conceitos e definindo alguns tipos masculinos}

Tendo em vista o processo de mudanças, com reflexos marcantes na publicidade, reformulamos uma proposta anterior de categorização de gênero (GARBOGGINI, 1999), procurando demonstrar os estereótipos mais freqüentes na publicidade da última década.

Um tipo, cada vez mais freqüente na publicidade, foi o que denominamos masculino equilibrado - o homem participante e sensível, representado desde a segunda parte da década de 1990. O homem em equilíbrio ou "o homem reconciliado", como define Badinter (1996), que mantém a masculinidade, admitindo sua sensibilidade sem problemas de exercer também funções tipicamente femininas. Ele sente-se seguro para tomar iniciativas tradicionalmente consideradas próprias de mulher. Nesta categoria podemos incluir o metrossexual, hoje, o tipo da moda mais fortemente mencionado na mídia. Observamos sua crescente aparição em anúncios de revistas européias. No eixo dos contraditórios, eles seriam localizados em pontos intermediários entre o não-masculino e o masculino tradicional, ou entre o masculino e o feminino no eixo dos contrários.

Para maior clareza, o masculino convencional seria aquele com características de conquistador e dominador, provedor do lar, o típico pai de família autoritário e pouco participativo que mantém o script definido para homem, o "homem de verdade". Ele define e executa tarefas convencionalmente masculinas. Para ele é inadmissível a igualdade de direitos e de funções entre homens e mulheres. Nesse tipo queremos incorporar tanto o estereótipo do pai de família como o do homem caçador e conquistador.

O não-masculino, no oposto do eixo dos contraditórios, seria o tipo que apresenta características femininas. Hipoteticamente, um homem que não se 
importa em aparentar e provar sua masculinidade. Este seria aquele com comportamentos ou características femininas, ou o que costuma ser categorizado como gay, sem entrar no mérito das preferências sexuais, mas apenas observando o visível na publicidade.

Esquema das relações feminino/masculino (FLOCH, 2001, p. 20)

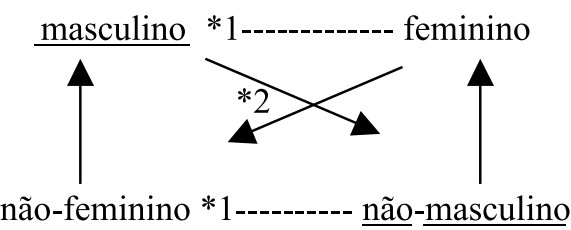

(INDICAÇÕES: EIXO DOS CONTRÁRIOS: *1; EIXO DOS CONTRADITÓRIOS: *2)

Consideramos, a seguir, apenas o eixo dos contraditórios, entre o masculino (tradicional) e o não-masculino, focalizando características visíveis nos enunciados, num eixo sintagmático da aparência da masculinidade, propondo um esquema desenvolvido com base na semiótica tensiva (FONTANILLE; ZILBERBERG, 2001). De um lado as representações mais diretas e realistas, ou mais racionais consideradas próprias de um "verdadeiro" homem que deve ser mais objetivo e produtivo. Do lado oposto, as representações mais suaves e delicadas ou os aspectos mais emocionais, mais associados às mulheres que são mais associadas à subjetividade e ao dar prazer - cama e mesa, tanto pela beleza, pelo sexo e pela boa alimentação, manutenção da casa e pelo bem estar dos filhos.

Os primeiros seriam os mais ligados aos valores masculinos tradicionais, que colocamos para o masculino, o homem que transparecia ser poderoso, provedor, machão, autoritário, dominador, distante da família, racional e infalivel e, em segundo, os valores mais próximos do feminino, que no caso em questão seriam associados ao não-masculino, aproximados da feminilidade pelo eixo sintagmático, enquanto se afasta do masculino tradicional na linha enviesada do contraditório. Quanto mais transparece o grau das características ligadas ao novo homem: sensivel, emotivo, frágil, falivel, próximo, companheiro, delicado e participativo da família, mais consideramos na categoria do oposto ao tipo tradicional. 
Esquema das tensões aplicado: Anúncios na categoria Homens

Valores masculinos tradicionais

\section{Masculino}

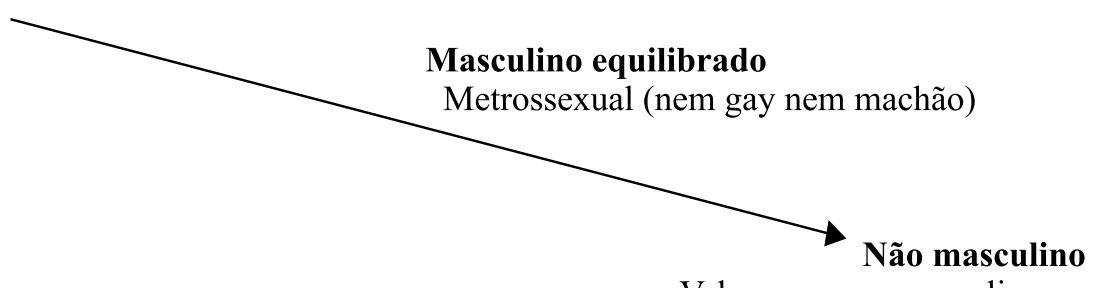

Valores menos masculinos

\section{Demonstrações na publicidade: $\mathrm{TV}$ e revista}

Foram raros os casos encontrados em comerciais de televisão na década de 1990, no Brasil, dessa nova representação do homem próximo das características menos masculinas, porém, no início do século XXI, essa tendência vem sendo adotada em anúncios, sobretudo, de marcas de perfumes e moda em revistas do tipo VIP no Brasil e Max, sua equivalente na França.

Depois de 1995, tanto na televisão como na revista, a representação paterna incorporou uma nova forma, mais participativa na educação e no acompanhamento dos filhos assim como colaborador da mulher nas funções do lar. Isso demonstra algum avanço no sentido da equiparação entre os sexos na família e no lar. Algumas empresas, principalmente multinacionais, como a Johnson e Johnson, Nestlé, Unilever - mostrando o caso específico do dentifrício Gessy-Cristal (analisado por GARBOGGINI, 1999), estão realizando, no Brasil, campanhas publicitárias de produtos como fraldas, cremes dentais e alimentos, nas quais os homens, como pais, aparecem orientando ou cuidando do filho. Muitas vezes, o enfoque mostra esse novo homem como um pai ativo e conhecedor das coisas da vida.

Quanto aos modelos masculinos tradicionais, os radicais, verificados na publicidade da televisão brasileira, na segunda metade dos anos 1990, o grande número de comerciais com esse enfoque apresentou uma forma de abordagem menos favorável aos machões, com algumas exceções como a da publicidade de algumas cervejas. No geral, não mais enaltecia os homens 
desse tipo como antes. Ao contrário, a maioria dos casos analisados usava de humor ou ironia para menosprezá-los ou até ridicularizá-los em seus papéis de pais autoritários ou maridos dominadores, enquanto os comerciais que representavam homens companheiros e participativos eram valorizados, tendo sido incentivados quando apresentados de forma positiva.

São diversos os casos de campanhas com abordagem negativa para o homem tradicional. A Brastemp, na década de 1990, apresentava vários modelos de homens desrespeitados pela esposa: em um ela o chamava de burro, em outro referia-se a ele como feio, ou sugeria, em um terceiro, que o havia traído porque ele não valia a pena. No mesmo período, numa publicidade de brinquedos Estrela, ao final de um diálogo, a mulher diz que o marido é um chato.

Também no comercial de TV para o refrigerante Sukita, do início desta década, um homem de meia idade tenta conquistar uma jovem e acaba sendo completamente ridicularizado.

Um modelo "machista" é o personagem de dois comerciais da Panela Panex, da década de 1990. O exagero de masculinidade é ironizada, provocando o riso e diminuindo a defesa dos receptores, contra os conteúdos preconceituosos veiculados.

Permite-se, nesse tipo de abordagem, a desvalorização dos sujeitos dos discursos, admitindo-se o desrespeito ao sexo masculino. Destacamos, ainda, o comercial, de temperos Sazon, de 1997/98, em que um velhinho é repreendido pela esposa por limpar a boca na toalha da mesa e no punho da camisa. Também, nessa linha, em um comercial dos freios Vargas, um homem, na figura paterna convencional, é totalmente humilhado pela família porque ele não se preocupou em fazer a revisão do carro para uma viagem de férias. Nesse caso, chega-se ao extremo de mostrar o filho chutando a perna desse pai irresponsável e, para finalizar a demonstração de insatisfação, o cachorro urina em sua perna.

Na utilização de tipos não masculinos, foram arrojadas algumas das poucas experiências encontradas em comerciais de TV, algo bastante novo na época na publicidade brasileira. Em três exemplos analisados, diferentes tipos de tratamento foram usados para o "não-masculino". A Folha de S.Paulo, em 1996, mostrava de forma séria um casal gay masculino. Porém, esse comercial teve uma veiculação mínima. Ao contrário, o comercial do molho Salsaretti de 1997, foi bem aceito, usando alguns atores e esportistas em representações afetadas. Eles imitavam mulheres, dando receitas culinárias. Num terceiro comercial, de 1998, para um Cursinho Universitário do Rio Grande do Sul, um jovem é surpreendido com uma cantada de conquista amorosa por 
parte de um colega. Esse, como o anterior, teve um caráter humorístico e foi até premiado pelo Clube de Criação de S.Paulo.

\section{Novas constatações em anúncios de revistas no início do século}

Entre os anúncios de revistas brasileiras pesquisadas no período de 2001 a 2005, vimos alguns gestos dos personagens que podem ser considerados fora do padrão masculino. Porém, nesse mesmo período, em anúncios de revistas francesas e italianas, encontramos, de forma mais acentuada, gestos e expressões masculinas bastante distanciadas daquelas esperadas para o masculino tradicional proposto neste estudo. Nos anúncios europeus, é muito mais comum encontrarmos imagens de homens que se olham, ou que se mostram em gestos e aparências delicados, próprios do gênero feminino. É comum a apresentação de homens de pele lisa, com gestos mais delicados, na forma de cruzamento de pernas, de colocação de mãos e com cortes de cabelo bastante diferentes daqueles realizados pelo antigo barbeiro.

Não parece existir agora tanto preconceito, ou ao menos existe a possibilidade de transitar entre esses valores mais ou menos masculinos, mais evidentes nas revistas do tipo "news" da Europa como a l'Express, Paris Match e Le nouvel observateur, testemunhadas na França entre 2001 e 2002 e l'Espresso, Panorama e Focus, observadas na Itália entre 2003 e 2004.

A campanha do perfume Eau Sauvage, da Dior, nas revistas francesas (2001-2002) utilizava como modelo o Corto Maltês, personagem italiano de revistas em quadrinhos, muito apreciado na Europa. Era transferido para o produto da Dior o tom de mistério por meio das características marcantes do personagem. É um exemplo do uso da fantasia associada ao masculino, funcionando também como negação de valores masculinos - "o homem deve ser realista e não sonhador".

A marca de perfumes Le male (o macho) de Jean-Paul Gautier, adotou nos últimos anos (2003-2004), um modelo que, na aparência, pode ser classificado como o terceiro tipo mencionado, mais próximo do estereótipo gay. Mantendo a referência ao marinheiro, pelo chapeuzinho, o garoto-propaganda apresenta uma pose pouco masculina, afrontando a imagem do "verdadeiro macho", numa ironia, ressaltada pela expressão num misto de meiguice e doçura. Suas tatuagens delicadas, mais próprias do gosto feminino, com bor- 


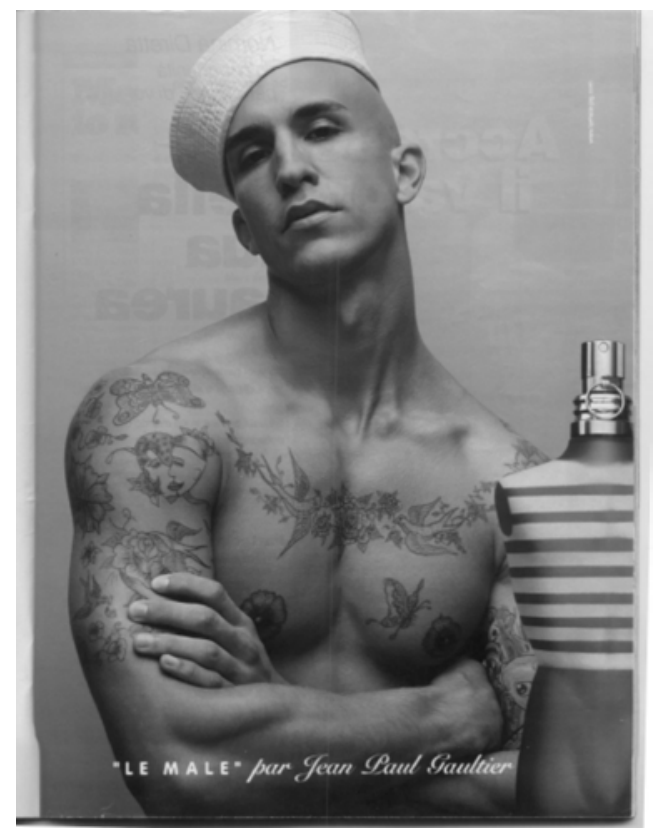

boletas, pássaros e flores, destacam sua pele lisa, sem nenhum pêlo no rosto e no peito nu (o anúncio aqui apresentado, foi verificado nas revistas $L$ 'Express França e L'Espresso e Panorama, Itália, em vários números em 2003 e 2004).

No Brasil, já na edição 44, de novembro de 1998, a revista de criação Meio e Mensagem dedicava-se exclusivamente à propaganda gay. Na chamada de capa declarava que crescia em todo o mundo as campanhas dirigidas ao público gay e propunha que, depois do sucesso e da inovação da campanha de Diesel Jeans, "vale a pena conhecer a linguagem, e irreverência e o desbunde dessa propaganda bem humorada". De lá para cá, no Brasil, essa tendência permaneceu escamoteada. As revistas mais abrangentes raramente veiculam anúncios com os estereótipos na linha do "não-masculino", como acontece freqüentemente na França e na Itália.

O nu masculino, sem a conotação gay, aparece, também, em anúncios franceses de perfumes masculinos (2001-2002) como o Kouros e o Caron. Nesses exemplos podemos perceber a presença de um misticismo que transporta o target a um mundo de fantasia e sensualidade prometido por esses perfumes, permitindo-lhes um desligamento da realidade e um distanciamento da vida prática e objetiva do trabalho. 


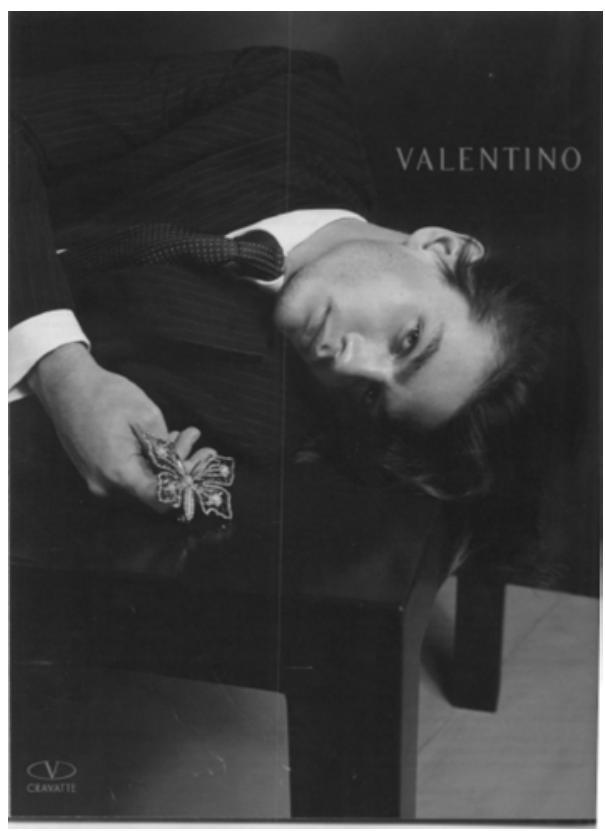

Outras marcas que ousam bastante são as grifes de alta classe como Gucci, Boss, Prada, Versace, Louis Vuitton, entre outros que usam, cada vez mais, o metrossexual como o modelo da marca Valentino (anúncio verificado na revista $L^{\prime}$ Espresso, 2004).

Esses estereótipos assumem uma representação de comportamento no paradigma do gênero associados às virtudes sensíveis do produto anunciado. Nesses casos, quanto mais se aproximam do "não-masculino", pelos gestos, aparências ou pelas roupas, mais apresentam valores existenciais, não utilitários, transportando o produto a um mundo de sonhos, a um universo desejado, algo que o produto promete dar aos consumidores como compensação. Esses modelos masculinos fazem o discurso feminino da sedução. No caso acima, o rapaz deita-se numa pose ao modo feminino. Seu rosto é limpo, sem barba, sobrancelhas bem delineadas. Vemos quase como se ele estivesse jogando seus cabelos.

Ainda, o discurso da transgressão às regras foi encontrado também, de forma positiva, na campanha francesa da marca de tecidos Falke. Ali, um rapaz de traços delicados olha para outro de forma sedutora. 
A ironia, em especial, é utilizada na publicidade brasileira, assumindo uma forma mais humorística, ao longo de um extenso período, nas campanhas do casal Unibanco, com a presença de Miguel Falabela, conhecido ator e assumido como "não-masculino".

Os anúncios brasileiros, das revistas de informações gerais, não apresentam mudanças marcantes como os europeus. Existem, apenas, casos de anúncios com modelos dos homens participativos, cuidando de filhos, como já havíamos testemunhado na TV no final da década passada. Esses aparecem, principalmente, em datas comemorativas, como Natal, ou próximo ao período do dia dos pais. Nessa linha, são freqüentes os anúncios de clínicas e hospitais, shopping centers, cartões de crédito e seguros. Buscam, em geral, destacar o lado sentimental masculino, destacando sua sensibilidade, tendo como finalidade a venda de produtos ou serviços para eles.

Podemos citar como exemplo o anúncio da Associação para o Estudo da Fertilidade, uma clínica de reprodução, que aproveita a comemoração do dia dos pais para homenageá-los e oferecer seus serviços. Mostra, num outdoor, um homem segurando no colo um bebê, simbolizando a paternidade e tem como texto: "O melhor presente para você, que não é papai... ....ainda" (2001). $\mathrm{Na}$ mesma linha, a maternidade São Luiz apresenta em anúncio de revista um pai embalando a filha nos braços. A intenção da publicidade é celebrar a data, esclarecendo que no dia dos pais o hospital pode ser chamado de "paternidade São Luiz" (2001). Nos dois anúncios, os personagens, pais e bebês, estão nus e a foto é tomada da cintura do homem para cima.

Contudo, no Brasil, é mais marcante a transformação por que passa a representação masculina nos anúncios de produtos de grifes internacionais. Essas, mantendo suas características de posicionamento de marca, carregam para cá aquelas novas representações masculinas, principalmente, para produtos de uso pessoal como perfumes, cremes, passando para serviços de aparência como institutos de beleza, clínicas de emagrecimento e academias de ginástica, bem próprios do estilo homem vaidoso, cada vez mais, incentivado aqui. Porém, a veiculação é mais restrita às revistas masculinas como VIP e, muito esporadicamente, nas revistas de notícias.

As análises dessas novas tendências não se esgotam neste texto, os anúncios podem ser revistos e estudados sempre sob novos ângulos e em níveis mais profundos, de acordo com a semiótica. É inevitável que muitos pontos tenham ficado para outra ocasião em função dos limites estabelecidos pelas regras desta publicação. 


\section{Para finalizar}

Sem dúvida, a interação entre a publicidade e a sociedade acontece. O reflexo das mudanças sociais masculinas começou a aparecer na publicidade brasileira na década de 1990 e pode ser provada em algumas campanhas nas quais os criadores não hesitaram em misturar contrastes. Elas se livraram das velhas fronteiras armadas pela moral da geração anterior e ousaram na utilização de novos padrões aceitáveis nos últimos anos. A cultura, evidentemente, está gerando uma perda de referências, uma generalização onde as sociedades procuram seus caminhos. Também, é a falta de fé a respeito das normas e dos valores tradicionais, permitindo o pluralismo, o ecletismo e favorecendo a emergência de novos comportamentos. A publicidade faz transparecer novos modos de vida. Uma multiplicidade que permite coabitar o antigo com o novo, dando margem ao surgimento de uma fragmentação crescente das sociedades ocidentais.

De forma global, o processo de ajuste à mudança é, freqüentemente, caracterizado como um período de confusão e incerteza para os homens, pois, embora as diretrizes dos papéis tradicionalmente masculinos já estejam sendo substituídas, aquelas que se ajustam, plenamente, aos novos papéis e expectativas ainda não estão, claramente, estabelecidas.

Podemos dizer que a roupa velha não serve mais e a nova ainda não ficou pronta.

De qualquer forma, estamos passando por um processo que possibilita aos homens relacionarem-se com o lado mais humanitário e livre da sua natureza. Há uma expectativa muito difundida de que a "nova" masculinidade vai resultar em um maior grau de expressão emocional e de preocupação com o relacionamento com os outros. Mesmo no Brasil, os homens estão tendo maior permissão para mostrar carinho, ternura e auto-expressão. E o papel do homem, no futuro, será aquele definido por meio da escolha individual que lhe proporcionará maior realização pessoal.

Em muitos dos comerciais analisados, vimos diversas vezes modelos de comportamento masculino tradicionais sendo ironizados na intenção de mostrálos como anti-heróis. Isto pode ser considerado um incentivo para a mudança. Apesar de observada a manutenção de representação masculina convencional é inegável, em muitos casos, a alteração do tratamento. É visível a forma como diversos personagens são construídos positivamente e outros que são reprovados, incentivando mudanças. Isso não significa uma generalização. Contudo, muitos exemplos mostram que o machão está em baixa. 
Não pode-se considerar como uma imposição a tendência de que os homens devem mudar totalmente, deve haver liberdade de escolha. Manterse mais ou menos fortes, enérgicos, individualistas, racionais e diretos é opcional. Porém, essas características poderão ter novas formas de expressão, caracterizadas por maior demonstração de sentimentos. Nesse sentido, o autoritarismo e a rígida distinção de papéis darão lugar à divisão do poder e compartilhamento dos respectivos papéis.

Tudo nos leva a pensar que as novas tendências publicitárias refletem essa cultura em mutação, mesmo que mais lentas no Brasil em comparação à França e Itália. Elas ilustram as mudanças mais profundas, reforçando-as simultaneamente.

Este debate, como de resto todos os debates sobre os comportamentos humanos, evidentemente, apenas esboça o quadro. Temos consciência de que tocamos de leve num assunto sobre o qual deveremos nos debruçar mais sistematicamente.

Propomos aos educadores aprofundar, também, sobre os símbolos articulados na construção da sociedade globalizada, mergulhando junto com nossos alunos na reflexão desse tema presente na mídia que nos envolve inexoravelmente.

Ao refletir os problemas e mudanças que afetam os homens no mundo todo, a propaganda, com ressonância internacional, pode até mesmo oferecer orientação aos homens, desde que assegure que o sentido de masculinidade seja preservado e, ao mesmo tempo, deixe claro os benefícios decorrentes da nova identidade expandida, bem como os de sua conscientização.

Dentre as mudanças a serem consideradas, os educadores poderiam propor análises da publicidade, observando e acompanhando, em paralelo, as alterações e avanços das formas de tratamento e os comportamentos humanos. Sobretudo, deveriam atentar para as dificuldades conseqüentes dessa transição da condição masculina em curso, geradora de novas formas de comportamento, papéis e funções na família, assim como suas mudanças estruturais. 


\section{REFERÊNCIAS}

BADINTER, E. XY A identidade masculina. Lisboa: ASA, 1996.

CUSCHNIR, L. Masculino: como ele se vê. São Paulo: Saraiva, 1994.

FALCK, J. Maschio metrosexual. L'Espresso, Roma, 130, p.130, 29 jan. 2004.

FLOCH, J. M. Documentos de Estudo do Centro de Pesquisas Sociossemióticas. São Paulo: Centro de Pesquisas Sociossemióticas, 2001.

FONTANILLE, J.; ZILBERBERG, C. Tensão e significação. São Paulo: Humanitas, 2001.

GARBOGGINI, F. B. A nova representação masculina na publicidade, uma leitura semiótica. In: GHILARDI, M. I.; BARZOTTO, V. Nas telas da mídia. Campinas: Alínea, 2002.

. O homem no espelho da publicidade. São Paulo, 1999. Tese (Doutorado) Ciências da Comunicação, ECA, Universidade de São Paulo.

IANNI, O. Teorias da globalização. Rio de Janeiro: Civilização Brasileira, 2000.

LIMA, O. de L. O brasileiro em números. Época, São Paulo, p. 82-88, 30 maio 2005.

NOLASCO, S. De Tarzan a Homer Simpson. Rio de Janeiro: Rocco, 2001.

RANDAZZO, S. A criação de mitos na publicidade. Rio de Janeiro: Rocco, 1997.

Texto recebido em 23 fev.2005

Texto aprovado em 24 maio 2005 